\title{
Estimates of Autozygosity Through Runs of Homozygosity in Farmed Coho Salmon
}

\author{
Grazyella M. Yoshida ${ }^{1}$ (D), Pablo Cáceres ${ }^{1}$, Rodrigo Marín-Nahuelpi ${ }^{1}$ (D), Ben F. Koop ${ }^{2}$ and \\ José M. Yáñez ${ }^{1,3, *}$ \\ 1 Facultad de Ciencias Veterinarias y Pecuarias, Universidad de Chile, Santiago 8820808, Chile; \\ grazyoshida@hotmail.com (G.M.Y.); pblo.caceres@gmail.com (P.C.); ro.nahuelpi@hotmail.es (R.M.-N.) \\ 2 Department of Biology, Centre for Biomedical Research, University of Victoria, \\ Victoria, BC V8W 2Y2, Canada; bkoop@uvic.ca \\ 3 Nucleo Milenio INVASAL, Concepción 4030000, Chile \\ * Correspondence: jmayanez@uchile.cl; Tel.: +56-22-978-55-33
}

Received: 3 April 2020; Accepted: 24 April 2020; Published: 30 April 2020

\begin{abstract}
The characterization of runs of homozygosity ( $\mathrm{ROH})$, using high-density single nucleotide polymorphisms (SNPs) allows inferences to be made about the past demographic history of animal populations and the genomic $\mathrm{ROH}$ has become a common approach to characterize the inbreeding. We aimed to analyze and characterize $\mathrm{ROH}$ patterns and compare different genomic and pedigree-based methods to estimate the inbreeding coefficient in two pure lines (POP A and B) and one recently admixed line (POP C) of coho salmon (Oncorhynchus kisutch) breeding nuclei, genotyped using a $200 \mathrm{~K}$ Affymetrix Axiom ${ }^{\circledR}$ myDesign Custom SNP Array. A large number and greater mean length of $\mathrm{ROH}$ were found for the two "pure" lines and the recently admixed line (POP C) showed the lowest number and smaller mean length of $\mathrm{ROH}$. The $\mathrm{ROH}$ analysis for different length classes suggests that all three coho salmon lines the genome is largely composed of a high number of short segments $(<4 \mathrm{Mb})$, and for POP $\mathrm{C}$ no segment $>16 \mathrm{Mb}$ was found. A high variable number of $\mathrm{ROH}$, mean length and inbreeding values across chromosomes; positively the consequence of artificial selection. Pedigree-based inbreeding values tended to underestimate genomic-based inbreeding levels, which in turn varied depending on the method used for estimation. The high positive correlations between different genomic-based inbreeding coefficients suggest that they are consistent and may be more accurate than pedigree-based methods, given that they capture information from past and more recent demographic events, even when there are no pedigree records available.
\end{abstract}

Keywords: admixture; autozygosity; inbreeding; run of homozygosity; Oncorhynchus kisutch; runs of homozygosity; pedigree

\section{Introduction}

Coho salmon (Oncorhynchus kisutch) is one of the six Pacific salmon species which can be found in North America and Asia [1]. In Chile, coho salmon farming was established during the late 1970s, date in which about a half of million eggs were imported from Oregon (USA) and the Kitimat river (British Columbia, Canada), giving origin to the basis of the commercial stocks in the country [2,3]. The first coho salmon breeding program started in 1992 with an increased growth rate as the main breeding objective. After four generations of selection for harvest weight, genetic gains of $\sim 10 \%$ per generation were reported $[2,3]$.

Genetic improvement programs for aquaculture species have been successfully established for increasing the productivity, for traits like growth and resistance against diseases [4,5]. However, one of the negative consequences of selective breeding is the accumulation of inbreeding, due to the use 
of related individuals for reproductive purposes [6]. As a consequence, a reduction in both the additive genetic variance and diversity is observed, as well as a decrease in the response to selection. Furthermore, inbreeding can result in inbreeding depression, defined as a reduction in fitness traits, including growth, survival and reproductive ability, due to the expression of detrimental recessive alleles given the existence of highly homozygous animals in the population [6,7]. Thus, monitoring and managing the inbreeding levels is critical in the operation of genetic improvement programs [8-10].

Pedigree-based inbreeding $\left(\mathrm{F}_{\text {ped }}\right)$ is traditionally estimated by calculating the probability that an individual inherits two alleles that are identical-by-descendent (IBD). When $\mathrm{F}_{\text {ped }}$ is used, the founder animals in the pedigree are considered unrelated. This assumption fails to capture the actual relatedness among animals from the base population [11]. Thus, pedigrees errors and incomplete or missing information might lead to incorrect or biased inbreeding estimates [12]. Furthermore, $\mathrm{F}_{\text {ped }}$ is computed as an average expectation (i.e., probabilities) and does not consider the stochastic nature of recombination during meiosis and the finite number of chromosomes [13]. The development of genomic technologies, including dense single nucleotide polymorphism (SNP) panels, creates opportunities to estimate inbreeding from genomic-based approaches, e.g., by using a genomic relationship matrix to infer identity-by-state (IBS) [14] or through ROH [15].

$\mathrm{ROH}$ is defined as continuous DNA segments that are homozygous in a particular individual [16], as a potential consequence of not random mating, demographic history of consanguineous mating due to parents transmitting identical haplotypes to their offspring [17]. Therefore, $\mathrm{ROH}$ may provide a good measure of individual genome-wide autozygosity, which is the homozygote status generated by IBD alleles, that resulted from genetic drift, population bottleneck, the mating of close relatives and selection $[13,18]$. Furthermore, the identification and characterization of $\mathrm{ROH}$ can provide insights into population history, structure and demographics over time, allowing to distinguish between recent and ancient inbreeding $[19,20]$. Long $\mathrm{ROH}$ segments are indicative of recent IBD (>16 Mb $=$ three generations), whereas short segments suggest ancient inbreeding ( $1 \mathrm{Mb}=50$ generations). The sum of all these segments is suggested to be an accurate estimate of the actual inbreeding level of an individual [21]. However, it also possible that not all small size $\mathrm{ROH}$ are due to IBD, but to identity-by-status (IBS) due to low recombination rates in specific regions of the genome, high linkage disequilibrium in non-related ancestors and genetic drift.

Inbreeding studies using genome-wide data were previously reported in humans [16,22,23], livestock [24-28], swine [29-31], sheep [32], goats [33] and river buffalo [34]. Several studies have shown that $\mathrm{ROH}$ provides a better measure of individual autozygosity at the genomic level and the possibility to identify specific IBD regions $[16,27,35]$. A recent study reported $\mathrm{ROH}$ patterns in rainbow trout populations to show the impact on selection on the genetic diversity in farmed stocks [36]. However, studies aimed to characterize $\mathrm{ROH}$ patterns and comparisons between coefficients of inbreeding using different approaches are scarce in aquaculture species, due to the need of deep and complete pedigree information and dense genomic information, which most of the time is insufficient. The objectives of this study were to identify and characterize the $\mathrm{ROH}$ patterns, and to compare inbreeding coefficients estimated using genomic and pedigree information in three farmed Chilean coho salmon populations.

\section{Methods}

\subsection{Coho Salmon Populations and Genotypes}

Two independent coho salmon populations, managed in two-year reproductive cycles (POP A and POP B) were used in this study and belong to the Pesquera Antares breeding program established in Chile in 1997. Both populations have undergone nine generations of selection for harvest body weight, since 1997 and 1998, POP A and B respectively. In addition, POP C is the progeny produced by mating sires from the seventh and dams from eighth generations of POP A and B, respectively. POP C was generated in 2013 to limit inbreeding levels, as suggested by Yáñez et al. [8]. The reproduction system, fish tagging and selection criteria of coho salmon populations were described previously $[37,38]$. 
Genomic DNA was extracted from fin clips of 88, 45 and 104 animals from POP A, B and C, respectively. The samples were genotyped using a $200 \mathrm{~K}$ Affymetrix Axiom ${ }^{\circledR}$ myDesign Custom SNP Array developed by the EPIC4 coho salmon genome consortium (http://www.epic-4.org) and built by ThermoFisher Scientific (San Diego, CA, USA) [39]. A genotype quality control was performed in Plink v1.09 [40] using the following parameters to exclude markers: Hardy-Weinberg Equilibrium (HWE) $p$-value $<1 \times 10^{-6}$, Minor Allele Frequency (MAF) $<0.01$ and call rate $<0.90$ for genotypes and samples. Furthermore, we retained only the SNP markers that commonly segregated among the three populations. Sampling protocols were approved by the Animal Bioethics Committee from Universidad de Chile (No. 08-2015) and all raw genotypic data are available at Figshare public repository (10.6084/m9.figshare.11931963).

\subsection{Principal Components and Admixture Analysis}

We used the software Plink v1.09 [40] to evaluate the genetic differentiation among the three coho salmon populations through principal component analysis (PCA). The first two PCAs were plotted using R scripts [41]. The population structure was also examined using a hierarchical Bayesian model implemented in STRUCTURE software v.2.3.4 [42]. We used three replicates of K values ranging from 1 to 12 , running of 50,000 iterations and burn-in of 20,000 iterations. To choose the best $K$ value we used the statistic $\Delta \mathrm{K}[43]$.

\subsection{Runs of Homozygosity}

Runs of homozygosity analysis was performed separately for all animals in each population using the R package detectRUNS [44]. The following constraints were applied to ROH detected: (i) the minimum number of SNPs included in an $\mathrm{ROH}$ was 50, (ii) the minimum length of an $\mathrm{ROH}$ was set at $1 \mathrm{Mb}$, (iii) the maximum distance between adjacent SNPs was $500 \mathrm{~Kb}$, (iv) maximum missing genotypes allowed was 5, (v) density was at least $1 \mathrm{SNP}$ per $50 \mathrm{~kb}$ and (vi) sliding windows approach was used to detect $\mathrm{ROH}$ for each genotyped animal at each marker position. $\mathrm{ROH}$ was classified into five-length classes: $1-2,2-4,4-8,8-16$ and $>16 \mathrm{Mb}$, identified as $\mathrm{ROH}_{1-2} \mathrm{Mb}, \mathrm{ROH}_{2-4} \mathrm{Mb}, \mathrm{ROH}_{4-8 \mathrm{Mb}}$, $\mathrm{ROH}_{8-16 \mathrm{Mb}}$, and $\mathrm{ROH}_{>16 \mathrm{Mb}}$, respectively.

Each $\mathrm{ROH}$ size class represent the number of generations from common ancestry, estimated as: $E\left(L_{I B D-H} \mid g c A\right)=\frac{100}{2 g c A}$, where $E\left(L_{I B D-H} \mid g c A\right)$ is the $\mathrm{ROH}$ segment length and $g c A$ is the number of generations from the common ancestor [13]. Thus, we would expect that $\mathrm{ROH}_{1-2} \mathrm{Mb}, \mathrm{ROH}_{2-4 \mathrm{Mb}}$, $\mathrm{ROH}_{4-8 \mathrm{Mb}}, \mathrm{ROH}_{8-16 \mathrm{Mb}}$, and $\mathrm{ROH}_{>16 \mathrm{Mb}}$ are dating to approximately $50,20,12.5,6$ and 3 generations ago by considering that the $1 \mathrm{cM}$ equals $1 \mathrm{Mb}$.

\subsection{Inbreeding Coefficient}

We estimated inbreeding coefficients using three different genomic methods and pedigree relationship matrix $\left(\mathrm{F}_{\mathrm{PED}}\right)$. Inbreeding coefficient based on runs of homozygosity $\left(\mathrm{F}_{\mathrm{ROH}}\right)$ was estimated for each animal based on all $\mathrm{ROHs}\left(\mathrm{ROH}_{\mathrm{ALL}}\right)$ and the $\mathrm{ROH}$ distribution of five different lengths ( $\mathrm{ROH}_{1-2 \mathrm{Mb}}, \mathrm{ROH}_{2-4 \mathrm{Mb}}, \mathrm{ROH}_{4-8 \mathrm{Mb}}, \mathrm{ROH}_{8-16 \mathrm{Mb}}$, and $\mathrm{ROH}_{>16 \mathrm{Mb}}$ ), as follows [16]:

$$
\mathrm{F}_{\mathrm{ROH}}=\frac{L_{R O H}}{L_{A U T O}}
$$

where $\mathrm{L}_{\mathrm{ROH}}$ is the sum of $\mathrm{ROH}$ lengths and $\mathrm{L}_{\mathrm{AUTO}}$ is the total length of the genome covered by the genome-wide SNP panel used, assumed to be $1685.79 \mathrm{Mb}$.

The $\mathrm{F}_{\mathrm{HOM}}$ was calculated based on genome-wide homozygous excess due to inbreeding as follows [45]:

$$
\mathrm{F}_{\mathrm{HOM}}=\frac{O_{\text {hom }}-E_{\text {hom }}}{\mathrm{N}-E_{\text {hom }}}
$$


where $O_{\text {hom }}$ is the observed number of homozygous markers in each individual, $E_{\text {hom }}$ is the expected number of homozygous markers under the Hardy-Weinberg equilibrium calculated from the allele frequencies estimated based on the sample and $\mathrm{N}$ is the total number of markers.

The $\mathrm{F}_{\mathrm{GRM}}$ was estimated using the genomic relationship matrix (GRM) [14], as follows:

$$
\mathrm{G}=\frac{\mathrm{ZZ}^{\prime}}{2 \sum_{\mathrm{i}=1}^{\mathrm{n}} \mathrm{p}_{\mathrm{i}}\left(1-\mathrm{p}_{\mathrm{i}}\right)^{\prime}}
$$

where $\mathrm{Z}$ is a genotype matrix that contains the $0-2 \mathrm{p}$ values for homozygotes, $1-2 \mathrm{p}$ for heterozygotes, and $2-2 p$ for opposite homozygotes, $\mathrm{p}$ is the allele frequency of SNP $i$. The diagonal elements of the matrix $G$ represent the relationship of the animal $j$ with itself, thus, the genomic inbreeding coefficient is calculated as $2 \mathrm{G}_{j j}-1$.

Pedigree-based inbreeding coefficients were estimated using the software INBUPGF90 [46]. The pedigree information used was provided by Pesquera Antares breeding program in Chile, for all animals born between 1998 and 2014, 1997 and 2013 and 1998 and 2013 for POP A, B and C respectively. Pearson correlation between genomic- and pedigree-based inbreeding coefficients were estimated within and across all populations using function cor.test in $\mathrm{R}$ [41].

\section{Results}

\subsection{Quality Control and Genomic Population Structure}

From an initial number of 135,500 markers, a total of 102,129 passed in the QC and were shared among the three populations. A number of $\sim 30 \mathrm{~K}, 21 \mathrm{~K}$ and $18 \mathrm{~K}$ markers for POP A, B and C, respectively were removed, most of them due to MAF criteria. In addition, a number of markers ranging from $3.2 \mathrm{~K}$ to $14.9 \mathrm{~K}$ were removed to select only common markers segregating across all three populations (Supplementary File 1).

In the PCA analysis, the first two eigenvectors, together, accounted for $29.2 \%$ of the total genetic variation and revealed three stratified populations (Figure 1). PCA1 included 22.15\% of the total genetic variation and generated the principal clusters to differentiate the three coho salmon populations, whereas PCA2 explained the variation present within each population.

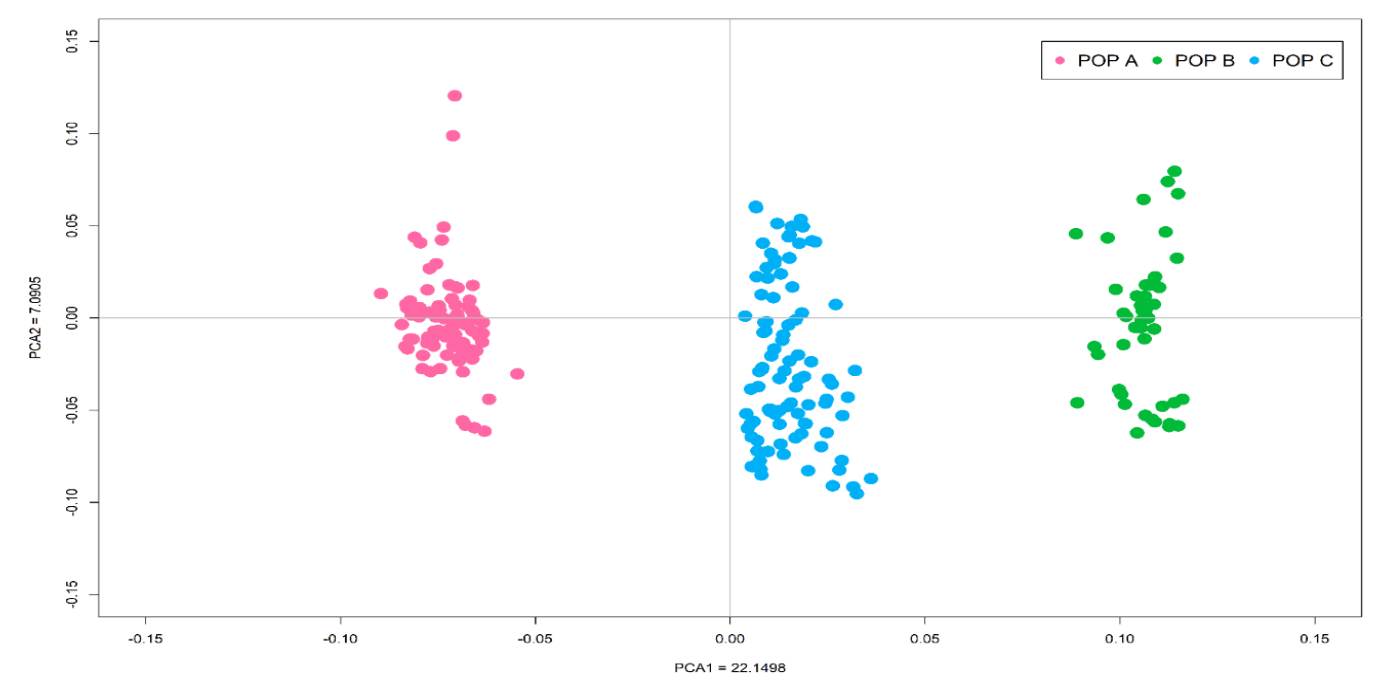

Figure 1. Principal component analysis of the autosomal genotypic data of three coho salmon populations.

The best K-value for admixture analysis was selected after performing several runs of MCMC for each $K$-value (ranging from 1 to 12 ), based on the statistic $\Delta K$ the best $K$-value was suggested to be $K=$ 4. These results indicated that for few individuals of POP A and POP B the proportion of ancestry come from a single cluster (green and yellow, respectively), and most of animals shared a proportion of 
their genome with each other, probably due to the similar origin of the source populations. In addition, Supplementary File 2 indicate a higher admixture level for most of animals from POP C, due to the recent cross between $\mathrm{POP} A$ and $\mathrm{B}$ to generate this population.

\subsection{Distribution of Runs of Homozygosity}

We identified $\mathrm{ROH}$ in all animals for coho salmon POP A and B, and in 103 out of 104 individuals for POP C. A total of 3250, 1497, and $266 \mathrm{ROH}$ and an average number of $36.93 \pm 7.13,35.65 \pm 8.64$, $2.65 \pm 1.27 \mathrm{ROH}$ per animal were identified for POP A, B and C, respectively. The mean ROH length was $6.47 \pm 7.39,7.17 \pm 7.69$ and $2.58 \pm 2.07 \mathrm{Mb}$ for POP A, B and C, respectively (Table 1) and the longest segment identified was $61.82 \mathrm{Mb}$, found in chromosome 2 for POP B (Supplementary File 3). The ROH analysis for different length classes suggests that for the three coho salmon populations the genome is mostly composed of a high number of short segments $\left(\mathrm{ROH}_{1-2 \mathrm{Mb}}, \mathrm{ROH}_{2-4 \mathrm{Mb}}\right)$. No segment was found for $\mathrm{ROH}_{>16 \mathrm{Mb}}$ in POP C.

Table 1. Total number of runs of homozygosity $(\mathrm{ROH})(\mathrm{N})$ per class, the average number of $\mathrm{ROH}$ per individual ( $\mathrm{N}$ Mean) and average length $(\mathrm{Mb})$ considered all $\mathrm{ROH}$ and by classes for three coho salmon populations.

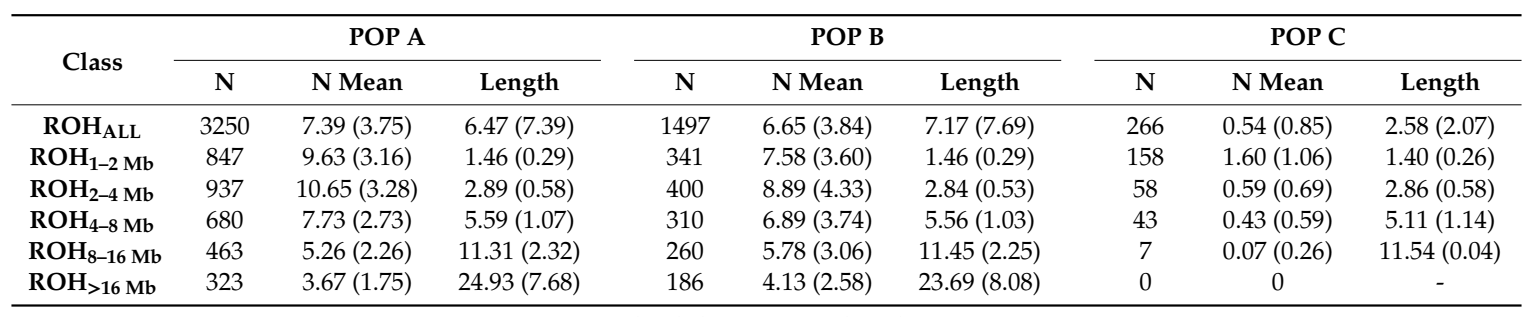

Standard deviation in brackets.

The average number of $\mathrm{ROH}$ identified differs between chromosomes and in low magnitude between populations. For POP A and POP B, most of the chromosomes resulted in the average number of $\mathrm{ROH}$ between one and two ROH per animal and more than two ROHs in chromosome Okis6 for POP A and Okis5, Okis18 and Okis19 for POP B, whereas for POP C all chromosomes have less than one $\mathrm{ROH}$ per individual (Figure 2). The average $\mathrm{ROH}$ length also differs between chromosomes and the population. POP A has two chromosomes (Okis5 and Okis11) with $\mathrm{ROH}$ segments greater than $10 \mathrm{Mb}$. POP B has five chromosomes (Okis3, Okis4, Okis6, Okis11 and Okis14) with ROH segments greater than $10 \mathrm{Mb}$; while all chromosomes in POP C have $\mathrm{ROH}$ segments smaller than $7 \mathrm{Mb}$ (Figure 3).

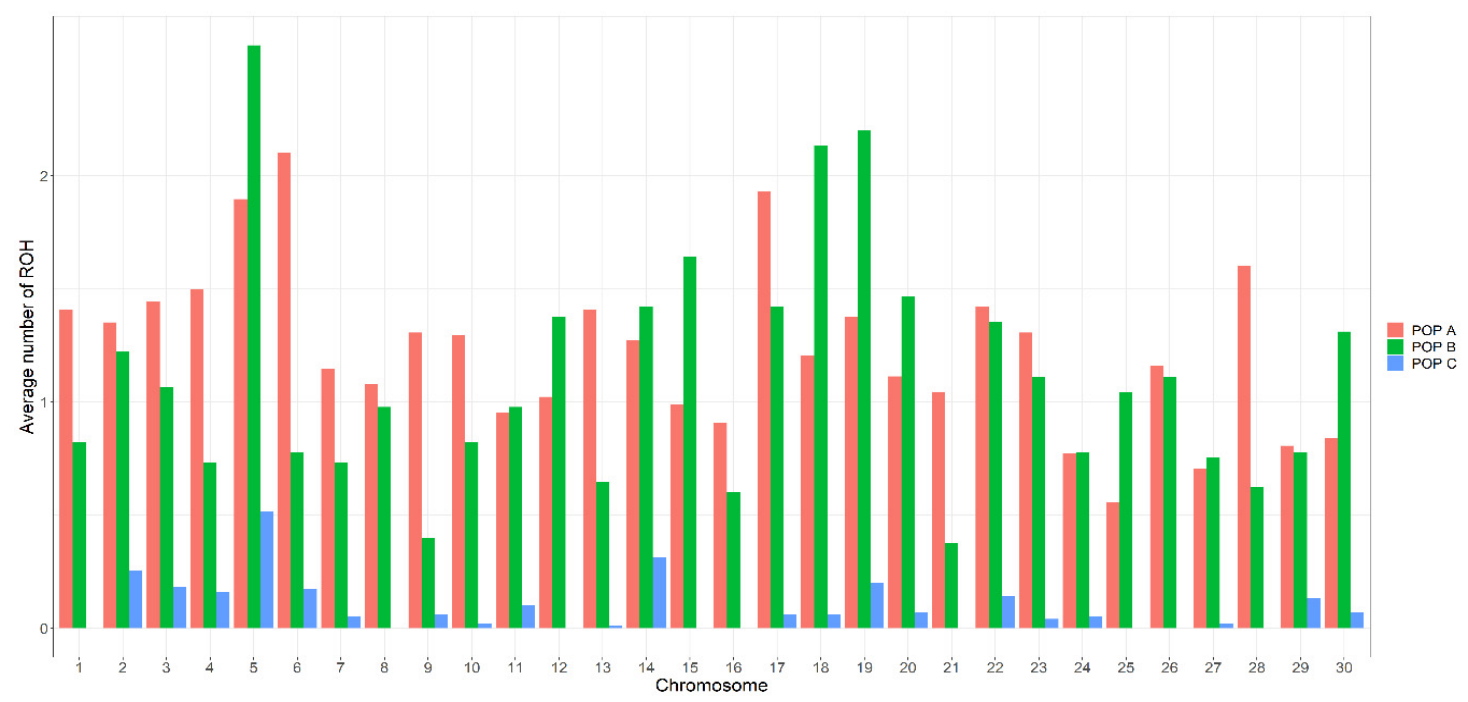

Figure 2. Distribution of the average number of $\mathrm{ROH}$ per individual for each chromosome in three coho salmon populations. 


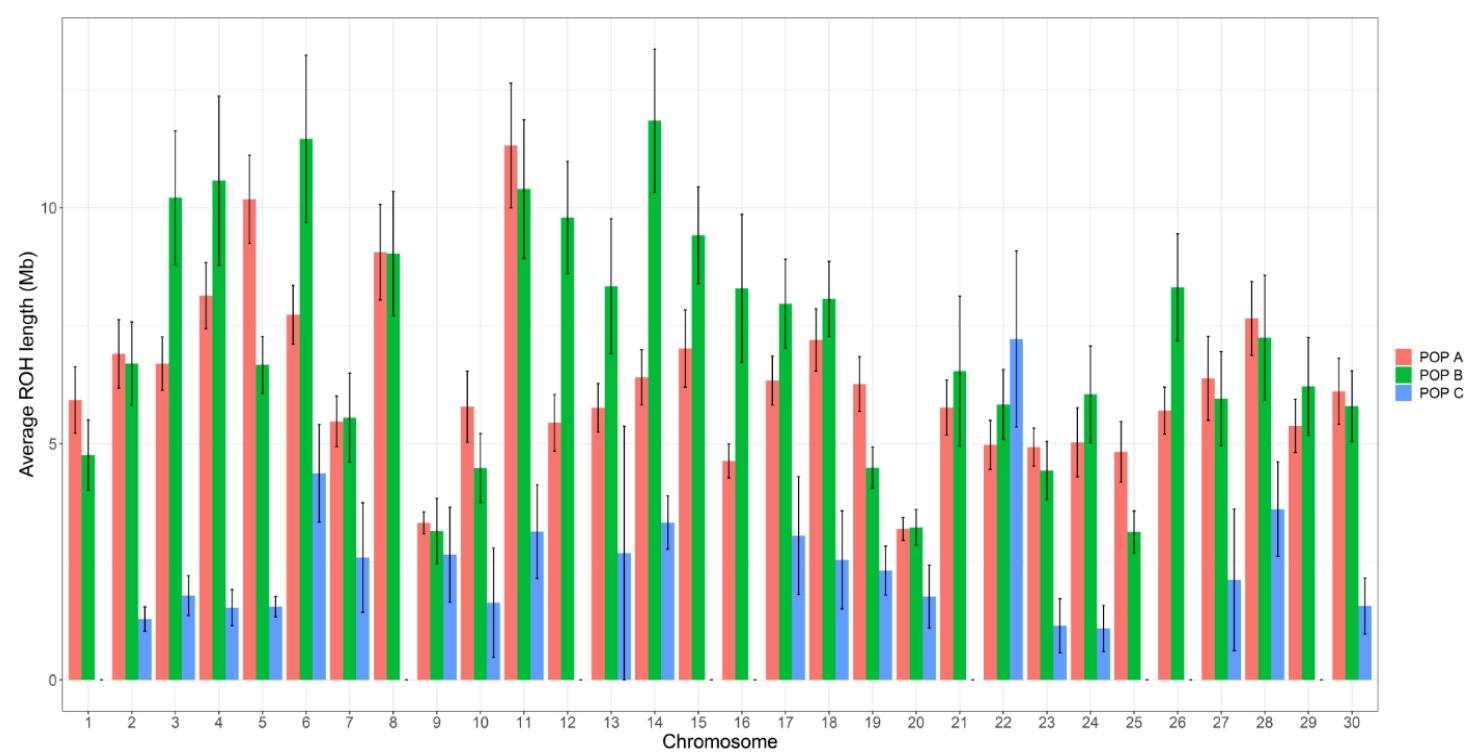

Figure 3. Average $\mathrm{ROH}$ length and standard error bars for each chromosome in three coho salmon populations.

Figure 4 shows the relationship between the total number of $\mathrm{ROH}$ and the total length of $\mathrm{ROH}$ for each animal across the three populations. A considerable difference between POP C and POP A or $\mathrm{B}$ was found. For POP C, all animals have a small number of $\mathrm{ROH}(<8)$ with total length $<25 \mathrm{Mb}$, whereas most individuals in POP A and B have at least $20 \mathrm{ROHs}$ with a total length $>100 \mathrm{Mb}$, with some individuals with segments covering more than $300 \mathrm{Mb}$. The number of ROHs and segment length per animal and per chromosome are shown in Supplementary File 3. The high number of segments $>10 \mathrm{Mb}$ in Okis5, Okis6 and Okis28, especially for POP A and B, suggests recent events of inbreeding, whereas the small segments as in Okis20 for POP A and B, and for most of the chromosomes for POP C, suggests more ancient inbreeding.

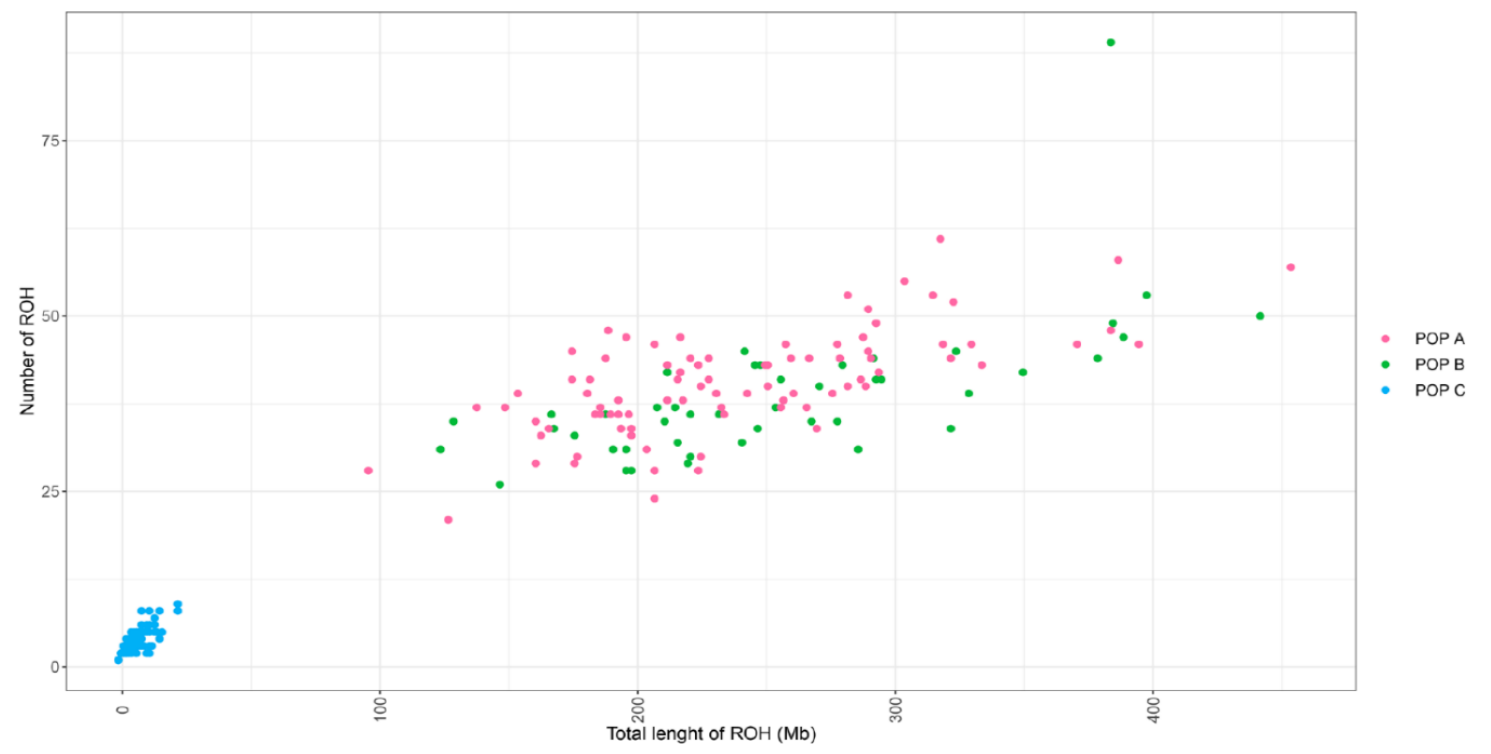

Figure 4. Relationship between the number of runs of homozygosity $(\mathrm{ROH})$ and total length of $\mathrm{ROH}$ $(\mathrm{Mb})$ per individual from each population.

\subsection{Genomic- and Pedigree-Based Inbreeding}

We used four different methods to estimate the inbreeding coefficient, from the information of $102 \mathrm{~K}$ markers and pedigree data (Table 2). The average inbreeding coefficient estimated using $\mathrm{ROH}$ 
was different between $\mathrm{ROH}$ classes, the values decreased when the $\mathrm{ROH}$ length segments increased for all populations. The mean value for $\mathrm{FROH}_{\mathrm{ALL}}$ was the same for both POP A and B (0.142 and 0.152 , respectively), but it was significantly different $(p<0.05)$ for POP C $(0.004)$ when compared to $\mathrm{POP} A$ or $\mathrm{B}$. The $\mathrm{F}_{\mathrm{HOM}}$ resulted in the lowest inbreeding values ranging from -0.036 to -0.105 for POP $\mathrm{A}$ and $\mathrm{C}$, respectively. The mean value for $\mathrm{F}_{\mathrm{GRM}}$ was different $(p<0.05)$ between the three populations, the highest and lowest values were reported for POP B and C, respectively, whereas the $F_{P E D}$ value was not different between POP A and B, but was significantly lower for POP C $(0.002$, $p<0.05)$. Additionally, we estimated the inbreeding coefficient based on the $\mathrm{ROH}$ per chromosome (Figure 5). POP A and B had the most chromosomes with inbreeding values higher than 0.2 , as in Okis5, Okis6 and Okis28 for POP A, and Okis5, Okis12, Okis14, Okis18 and Okis26 for POP B, whereas lower values were found for POP C and for most of the chromosomes the inbreeding was equal to zero.

Table 2. The number of individuals (N), mean and standard deviation (SD) of inbreeding coefficients using runs of homozygosity (FROH) for different $\mathrm{ROH}$ length, based on the excess of homozygosity $\left(\mathrm{F}_{\mathrm{HOM}}\right)$, genomic relationship matrix $\left(\mathrm{F}_{\mathrm{GRM}}\right)$ and pedigree-based relationship matrix $\left(\mathrm{F}_{\mathrm{PED}}\right)$ for each coho salmon population.

\begin{tabular}{|c|c|c|c|c|c|c|c|c|c|}
\hline \multirow{2}{*}{ Class } & \multicolumn{3}{|c|}{ POP A } & \multicolumn{3}{|c|}{ POP B } & \multicolumn{3}{|c|}{ POP C } \\
\hline & $\mathbf{N}$ & Mean & SD & $\mathbf{N}$ & Mean & SD & $\mathbf{N}$ & Mean & SD \\
\hline $\mathrm{FROH}_{1-2 \mathrm{Mb}}$ & 88 & $0.142^{\mathrm{a}}$ & 0.038 & 45 & $0.152^{a}$ & 0.044 & 103 & $0.004^{b}$ & 0.003 \\
\hline $\mathrm{FROH}_{2-4 \mathrm{Mb}}$ & 88 & $0.133^{\mathrm{a}}$ & 0.038 & 45 & $0.145^{\mathrm{a}}$ & 0.044 & 73 & $0.003^{b}$ & 0.003 \\
\hline $\mathrm{FROH}_{4-8 \mathrm{Mb}}$ & 88 & $0.115^{\mathrm{a}}$ & 0.037 & 45 & $0.129^{a}$ & 0.043 & 47 & $0.002^{b}$ & 0.002 \\
\hline $\mathrm{FROH}_{8-16 \mathrm{Mb}}$ & 88 & $0.090^{\mathrm{a}}$ & 0.036 & 45 & $0.104^{a}$ & 0.043 & 7 & $0.000^{b}$ & 0.002 \\
\hline $\mathrm{FROH}_{>16 \mathrm{Mb}}$ & 85 & $0.054^{\mathrm{a}}$ & 0.028 & 45 & $0.062^{\mathrm{a}}$ & 0.036 & - & - & - \\
\hline FROH $_{\text {ALL }}$ & 88 & $0.142^{\mathrm{a}}$ & 0.038 & 45 & $0.152^{\mathrm{a}}$ & 0.044 & 103 & $0.004^{b}$ & 0.003 \\
\hline $\mathrm{F}_{\text {HOM }}$ & 88 & $-0.036^{b}$ & 0.048 & 45 & $-0.069^{a}$ & 0.056 & 104 & $-0.105^{c}$ & 0.011 \\
\hline FGRM $_{\text {GR }}$ & 88 & $0.145^{\mathrm{b}}$ & 0.037 & 45 & $0.193^{a}$ & 0.040 & 104 & $0.051^{c}$ & 0.009 \\
\hline$F_{P E D}$ & 88 & $0.071^{\mathrm{a}}$ & 0.021 & 45 & $0.076^{a}$ & 0.027 & 104 & $0.002^{b}$ & 0.012 \\
\hline
\end{tabular}

Different letters in each row indicate statistical significance for the comparison of methods for inbreeding estimation within populations $(p<0.05)$.

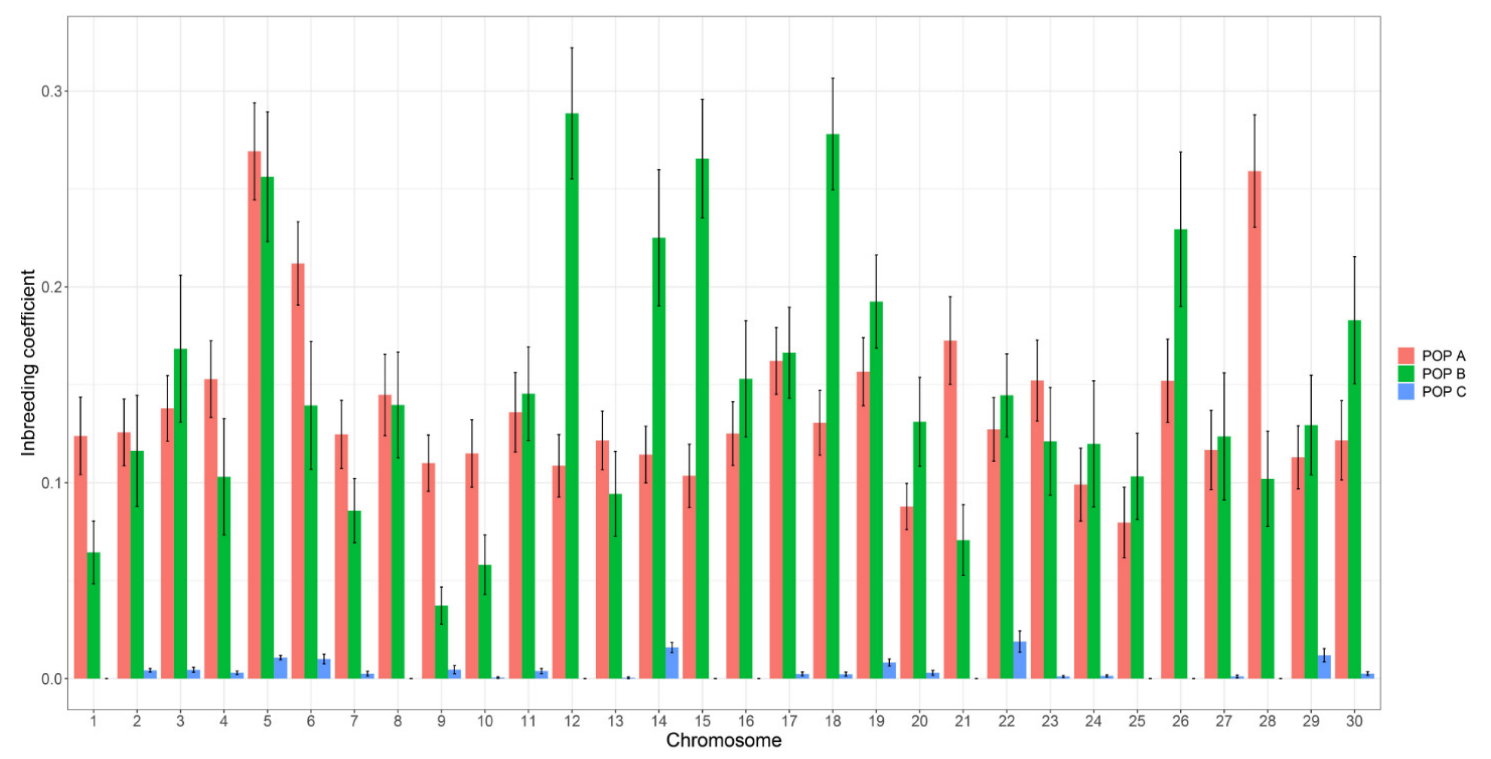

Figure 5. Distribution of average inbreeding coefficients estimated using $\mathrm{ROH}$ for each chromosome in three coho salmon populations. Standard error bars were computed among individuals from the same population.

The Pearson correlation between different genomic methods to estimate the inbreeding coefficient suggested a high positive correlation $(>0.82, p<0.001)$ for POP A and POP B (Supplementary File 
4 and 5, respectively). Correlation between different $\mathrm{ROH}$ length classes decreased in function with the comparison between shorter and longer segments, e.g., highest correlation between $\mathrm{ROH}_{1-2 \mathrm{Mb}}$ and $\mathrm{ROH}_{2-4 \mathrm{Mb}}$ and lowest between $\mathrm{ROH}_{1-2 \mathrm{Mb}}$ and $\mathrm{ROH}_{>16 \mathrm{Mb}}$. The lowest correlation values among genomic methods was reported between $\mathrm{ROH}_{>16 \mathrm{Mb}}$ and both $\mathrm{ROH}_{\mathrm{HOM}}$ and $\mathrm{ROH}_{\mathrm{GRM}}$. In addition, for POP A and POP B low correlation values were found, respectively, ranging from 0.35 to 0.39 $(p<0.01)$, between genomic methods and $\mathrm{F}_{\mathrm{PED}}$.

Different patterns of correlations were observed for POP C, compared to POP A and B, probably due to the low inbreeding level of this recently admixed population. Medium to high positive correlation was reported between the $\mathrm{ROH}$ classes ( 0.54 to $0.94, p<0.001$ ), and a correlation equal to unity was observed between $\mathrm{ROH}_{\mathrm{HOM}}$ and $\mathrm{ROH}_{\mathrm{GRM}}$. For other correlations, small values (ranged from 0.28 to 0.34 ) or not different from zero were observed (Supplementary File 6).

The across-populations Pearson correlation coefficients between different genomic- and pedigree-based inbreeding estimates ranged between 0.56 and 1.00, with the minimum and maximum correlation values found between $\mathrm{F}_{\mathrm{HOM}}-\mathrm{F}_{\mathrm{PED}}$ and $\mathrm{FROH}_{1-2 \mathrm{MB}}-\mathrm{FROH}_{2-4 \mathrm{MB}}-\mathrm{FROH}_{4-8 \mathrm{MB}}$ comparisons, respectively. All correlation values among inbreeding coefficient calculated for all individuals across populations are shown in Supplementary File 7.

\section{Discussion}

The first two principal components explained more than $29 \%$ of the total genetic variation for the three populations studied, which were separated into three different clusters. The admixture results are in agreement with the recent event of hybridization of POP A and B to generate POP C, where the genetic differentiation between POP A and B may have been be partly generated by differences in the base population, which can have a pronounced effect on allele frequencies [47]. In addition, considering that POP A and B have been independently selected by at least eight generations each, differences in the selection processes, as well as the environmental conditions and drift, may have influenced the differences observed in Supplementary File 2.

The $\mathrm{ROH}$ patterns seem to be differentially distributed within specific genomic regions, same as the inbreeding values between chromosomes. The highest autozygosity, e.g., in chromosome Okis 5 and Okis6 for POP A and B, is likely the consequence of artificial selection [28], considering that these populations have been under genetic selection for harvest weight for at least eight generations. A ROH study in humans [48] suggested that the homozygosity segments are more common in regions with high linkage disequilibrium (LD) and low recombination rates. Thus the highest mean levels of LD found in Okis5 and Okis6 in animals from the same populations [39] are in accordance with the two chromosomes with the larger $\mathrm{ROH}$ sizein the present study.

Differences in the number of $\mathrm{ROH}$ and segment length was observed within and across populations. The greater number of $\mathrm{ROH}$ in POP A compared to POP B can be due to higher sample size in the former, considering that the average number of $\mathrm{ROH}$ per animal had small variation between populations. The differences in average $\mathrm{ROH}$ length may be due to recent inbred mating or other demographic processes along the time in the different populations, which can generate different distribution of long and short $\mathrm{ROH}$ segments [49]. Furthermore, the intense artificial selection might have altered the allele frequency and increase the IBD haplotypes and created long $\mathrm{ROH}$ in specific regions of the genome [28]. In contrast, the shorter segments and smaller number of $\mathrm{ROH}$ in POP C when compared against both POP A and B may be the result of recent population admixture between these populations. Furthermore, animals from the same population might have the same total $\mathrm{ROH}$ lengths but a variable number of segments, which is probably the result of different distances from common ancestors [25]. Interestingly, for both POP A and B, the length class $\mathrm{ROH}_{2-4} \mathrm{Mb}$ has more $\mathrm{ROH}$ than $\mathrm{ROH}_{1-2} \mathrm{Mb}$. These differences can be due to the criteria adopted to identify $\mathrm{ROH}$ or an inherent characteristic of these populations. There is no consensus on the best parameters to characterize $\mathrm{ROH}$ patterns [36]; thus, here we used the minimum number of $50 \mathrm{SNPs}$ and the length of $1 \mathrm{Mb}$ to define a ROH segment. We chose the current parameters due to the historical demographics of coho salmon in Chile. The $\mathrm{ROH}_{2-4 \mathrm{Mb}}$ 
should date from about 20 generations ago (approximately 40 years considering the generation interval of two years), which corresponds to the introduction of coho salmon in Chile at the end of the 1970s, to begin the establishment of Chilean brood stocks [2,39].

Based on information of $\mathrm{ROH}$ length it is possible to infer the number of generations for inbreeding events [50]. The $\mathrm{ROH}$ due to ancient origin tend to be shorter, e.g., $\mathrm{ROH}_{1-2} \mathrm{Mb}, \mathrm{ROH}_{2-4} \mathrm{Mb}$ and $\mathrm{ROH}_{4-8 \mathrm{Mb}}$ date from 50, 20 and 12.5 generations ago, respectively. In contrast, recent $\mathrm{ROH}$ are longer, due to the small probability of breaking down the segments that are IBD by means of recombination events. Thus, the $\mathrm{ROH}_{8-16 \mathrm{Mb}}$ and $\mathrm{ROH}>16 \mathrm{Mb}$ are dated to six and three generations ago, respectively [22,50]. For both POP A and B it was possible to identify short and long segments in most of the animals analyzed, whereas in the POP C a small number of animals $(n=7)$ presented $\mathrm{ROH}_{8-16 \mathrm{Mb}}$ and none $\mathrm{ROH}_{>16 \mathrm{Mb}}$.

In recent years, some studies have investigated different genomic methods to estimate inbreeding coefficients in livestock $[11,25,28,35,51,52]$, pigs [29,30,53,54] and goats [55-57]. Recently, ROH studies in rainbow trout [36] and turbot [58] reported different average $\mathrm{ROH}$ length for these aquaculture species; $4 \mathrm{Mb}$ and $0.77 \mathrm{Mb}$ rainbow trout and turbot, respectively. These differences can be explained due to the genome size, that is 3.5-fold smaller in turbot [58], and also based in different demographic history in the populations assessed. The greater average $\mathrm{ROH}$ segments found in the present study (6.6 Mb and 7.2 Mb for POP A and POP B, respectively) are most likely due to high selection intensity during almost eight generations in these coho salmon population and the mate allocation strategies that resulted in high level of inbreeding, and consequently longer $\mathrm{ROH}$ segments. However, this is the first study aimed at characterizing the $\mathrm{ROH}$ patterns and comparing different genomic- and pedigree-based methods to estimate inbreeding coefficients in farmed coho salmon populations. The pedigree-based inbreeding coefficient, is a simple method that requires recording genealogy information, but does not account for the autozygosity differences among animals with the same inbreeding history. Furthermore, considering that the founder animals are unrelated pedigree-based inbreeding estimates may lead to underestimation of autozygosity levels [11]. In contrast, with the availability of high-density SNP information, inbreeding can be accurately measured, even without pedigree information [15]. $\mathrm{ROH}$ can provide a better estimation of whole-genome autozygosity levels, by identifying IBD segments with great accuracy [51], and based on length of the ROH segments the ancient and contemporary inbreeding can be reported [29].

A comparison of inbreeding coefficients, showed that $\mathrm{F}_{\mathrm{GRM}}$ gave the highest values, especially for B and C, probably because the alleles IBD and IBS are not differentiated for $F_{\mathrm{GRM}}$ [11]. This result is in agreement with results previously found in humans, cattle, and simulation studies $[11,15,16]$. $\mathrm{F}_{\mathrm{HOM}}$ resulted in negative inbreeding values for all populations, suggesting that the individuals have lower levels of homozygosity than expected in the reference population under Hardy-Weinberg equilibrium [59] and underestimated values should be expected [60]. The FPED for POP A and POP $B$ were smaller than values estimated using $\mathrm{FROH}_{\mathrm{ALL}}$ and $\mathrm{F}_{\mathrm{GRM}}$, but are in accordance with the values estimated for the same populations using previous generations $[8,10]$. The FED $_{\text {PEn be easily }}$ underestimated when pedigree information of less than 20 generations is used [60]. The difference between $\mathrm{F}_{\mathrm{ROH}}$ and $\mathrm{F}_{\mathrm{PED}}$ could also be due to the unknown pedigree information before base population, which in practical terms means that inbreeding levels for founding animals were not zero.

$\mathrm{ROH}$ can be identified for each genotyped animal, allowing to detect specific location in the genome with high levels of autozygosity, i.e., along chromosomes [61]. In this regard, we used the Pearson correlation to evaluate the agreement between $\mathrm{F}_{\mathrm{ROH}}$ and other approaches to estimate genomic inbreeding $\left(\mathrm{F}_{\mathrm{GRM}}\right.$ and $\left.\mathrm{F}_{\mathrm{HOM}}\right)$. Correlations between $\mathrm{F}_{\mathrm{GRM}}$ and $\mathrm{F}_{\mathrm{ROH}}$ decreased while decreasing size of $\mathrm{ROH}$ classes probably due to that $\mathrm{G}$ matrix that is based in individual loci, whereas $\mathrm{F}_{\mathrm{ROH}}$ is based on chromosomal segments, and the $\mathrm{F}_{\mathrm{GRM}}$ cannot distinguish between alleles that are IBD and IBS [62]. Another reason which may explain this pattern is that $\mathrm{ROH}$ is the sum of large and short segments, and $\mathrm{ROH}$ classes of smaller size could be more informative on the homozygosity status across the genome when compared to classes of larger $\mathrm{ROH}$ segments. It has also been previously suggested that 
both $\mathrm{F}_{\mathrm{GRM}}$ and $\mathrm{F}_{\mathrm{HOM}}$ are strongly dependent on allele frequencies, especially for populations with divergent allele frequencies (high level of heterozygosity and some rare alleles with small frequency), which can result in misleading IBD $[51,63]$. The high correlations $(>0.80)$ found between $\mathrm{F}_{\mathrm{ROH}}$ and other genomic inbreeding estimates for POP A and B, and moderate to strong positive correlation between genomics methods used to estimate inbreeding coefficients has been reported for different species $[27,29,62,64]$, suggesting that the extent of homozygosity in a genome can be accurately used to predict the proportion of the genome that is IBD. In contrast, we found low correlation between $\mathrm{F}_{\mathrm{ROH}}$ in different length classes and $\mathrm{F}_{\mathrm{GRM}}$ and $\mathrm{F}_{\mathrm{HOM}}$ for the POP $\mathrm{C}$, which makes sense considering that this is a recently admixed population, and the correlation might be affected by the average degree of actual homozygosity of population $[27,35]$.

The genomic-based inbreeding method correlated moderately or poorly with pedigree data, showing values lower than 0.39 . Similarly weak or no correlation was reported for cattle $[24,51,52]$, whereas a moderate to strong positive correlation was described by some authors $[15,16,35,65]$. An increase in the correlation between genomic- and pedigree-based inbreeding as the pedigree depth increases is expected [24]. Here we used the complete pedigree information of nine generations for both POP A and POP B, whereas for POC C, a pedigree depth of eight generations was used. In a previous pedigree-based inbreeding study using the same broodstock population of POP A (7th generation) and POP B (8 th generation), an increasing tendency for inbreeding values in the last four generations was reported for both populations [8] and a continued inbreeding accumulation until 9 th generation used in our study is well-known. Thus, we expected a higher correlation between long $\mathrm{ROH}$ segments $\left(\mathrm{ROH}_{8-16 \mathrm{Mb}}\right.$, and $\left.\mathrm{ROH}_{>16 \mathrm{Mb}}\right)$ and $\mathrm{F}_{\mathrm{PED}}$ values. The weak or no correlation may be explained by the depth of pedigree records [61], incorrect or incomplete pedigree information [51]. The $F_{\text {PED }}$ assumed that the founder individuals are unrelated [11], does not consider the stochastic nature of recombination and the persistence of ancestral short segments through time, due to the lack of recombination in specific regions [27]. These facts suggest that the F $_{\text {PED }}$ may not reflect true inbreeding values. In addition, the correlation between genomic and pedigree-based inbreeding can be also affected by the parameters to determine $\mathrm{ROH}[35,36,66]$ and the population sample size $[15,24]$. Here we chose the parameters to identify $\mathrm{ROH}$ segments based on those reported in previous studies $[27,36,52,65,67,68]$. Regarding sample size, the POP B is the population with the smallest sample size $(n=45)$; however, was the only one that resulted in significant correlations between genomic- and pedigree-based inbreeding levels. Moreover, various studies on the characterization of $\mathrm{ROH}$ patterns in production species used similar or smaller sample size [26,35,36,69].

A relatively large effective population size ( $\mathrm{Ne})$, ranged from 50 to 200, is recommended to maintain the control of inbreeding in the medium-term [70]. However, decline in the historical $\mathrm{Ne}$ was reported for animals from the same population as POP A [39]. The reduction may be due to the prioritization of genetic gain using high selection pressure without putting strong control on the family contribution for each generation [8]. Consequently, mating close relatives is more probable, which results in a high level of inbreeding and the creation of long ROH segments for both POP A and B. Therefore, to increase the effective population size and to limit the inbreeding level [8], POP $\mathrm{C}$ was generated. According to our results, this strategy was effective in reducing the inbreeding levels and changing the patterns of $\mathrm{ROH}$, clearly differentiating from POP A and $\mathrm{B}$. These results are in accordance with some studies $[15,35,55,57]$ that suggest that high heterogeneity populations due admixture or crossbreeding lines contributed to the breakdown of long homozygous segments and reduced the inbreeding levels in captive populations.

\section{Conclusions}

We found different numbers and lengths of runs of homozygosity in three coho salmon populations included in the study. Moreover, the inbreeding coefficient estimated using genomic or pedigree-based methods varied among populations. The higher correlations between genomic-based inbreeding methods, except for POP C and most likely due to recent admixture history, suggests that genomic 
approaches are more accurate to estimate autozygosity levels, and thus, must be used as the methods of choice when pedigree information is inaccurate, incomplete or unavailable.

Supplementary Materials: The following are available online at http://www.mdpi.com/2073-4425/11/5/490/s1, Table S1: Summary of results from quality control of SNP genotypes. Figure S1: Admixture clustering of the three coho salmon population for $K=4$. Figure S2: Runs of homozygosity patterns for all chromosome coho salmon populations. Figure S3: Scatterplots and Pearson correlation of inbreeding coefficients for POP A. Figure S4: Scatterplots and Pearson correlation of inbreeding coefficients for POP B. Figure S5: Scatterplots and Pearson correlation of inbreeding coefficients for POP C. Figure S6: Scatterplots and Pearson correlation of inbreeding coefficients across coho salmon populations.

Author Contributions: G.M.Y. performed the analysis and wrote the initial version of the manuscript. P.C. and R.M.-N. contribute with writing. B.F.K. develop the SNP array. J.M.Y. conceived and designed the study; contributed to the discussion and writing. All authors have read and agreed to the published version of the manuscript.

Funding: This research was partially funded by Government of Canada through EPIC4 (Enhanced Production in Coho: Culture, Community, Catch) from Genome Canada, Genome British Columbia, and Genome Quebec.

Acknowledgments: We thank the Government of Canada through Genome Canada, Genome British Columbia, and Genome Quebec to supported this research that was carried out in conjunction with the projected EPIC4 (Enhanced Production in Coho: Culture, Community, Catch). We also would like to acknowledge Pesquera Antares S.A., which provided the fish used in this study. GMY is supported by Fondecyt/Conicyt Postdoctoral Grant n. 3190553, and JMY is supported by Núcleo Milenio INVASAL funded by Chile's government program, Iniciativa Cientifica Milenio from Ministerio de Economia, Fomento y Turismo.

Conflicts of Interest: The authors declare that the research was conducted in the absence of any commercial or financial relationships that could be construed as a potential conflict of interest.

\section{References}

1. Groot, C.; Margolis, L. Pacific Salmon Life Histories; UBC Press: Vancouver, BC, Canada, 1991; ISBN 9780774803595.

2. Neira, R.; Lhorente, J.P.; Yáñez, J.M.; Araneda, M.; Filp, M. Evolution of Coho Salmon (Oncorhynchus kisutch) Breeding Programs. In Proceedings of the 10th World Congress of Genetics Applied to Livestock Production, Vancouver, BC, Canada, 17-22 August 2014; pp. 1-6.

3. Lhorente, J.P.; Araneda, M.; Neira, R.; Yáñez, J.M. Advances in genetic improvement for salmon and trout aquaculture: The Chilean situation and prospects. Rev. Aquac. 2019, 11, 340-353. [CrossRef]

4. Gjedrem, T. Genetic improvement of cold-water fish species. Aquac. Res. 2000, 31, 25-33. [CrossRef]

5. Gjedrem, T.; Robinson, N.; Rye, M. The importance of selective breeding in aquaculture to meet future demands for animal protein: A review. Aquaculture 2012, 350-353, 117-129. [CrossRef]

6. Howard, J.T.; Pryce, J.E.; Baes, C.; Maltecca, C. Invited review: Inbreeding in the genomics era: Inbreeding, inbreeding depression, and management of genomic variability. J. Dairy Sci. 2017, 100, 6009-6024. [CrossRef] [PubMed]

7. Gallardo, A.; Garc1, X.; Paul, J.; Neira, R. Inbreeding and inbreeding depression of female reproductive traits in two populations of Coho salmon selected using BLUP predictors of breeding values. Aquaculture 2004, 234, 111-122. [CrossRef]

8. Yáñez, J.M.; Bassini, L.N.; Filp, M.; Lhorente, J.P.; Ponzoni, R.W.; Neira, R. Inbreeding and effective population size in a coho salmon (Oncorhynchus kisutch) breeding nucleus in Chile. Aquaculture 2014, 420-421, S15-S19. [CrossRef]

9. Ponzoni, R.W.; Khaw, H.L.; Nguyen, N.H.; Hamzah, A. Inbreeding and effective population size in the Malaysian nucleus of the GIFT strain of Nile tilapia (Oreochromis niloticus). Aquaculture 2010, 302, 42-48. [CrossRef]

10. Yoshida, G.M.; Yáñez, J.M.; de Oliveira, C.A.L.; Ribeiro, R.P.; Lhorente, J.P.; de Queiroz, S.A.; Carvalheiro, R. Mate selection in aquaculture breeding using differential evolution algorithm. Aquac. Res. 2017, 48, 5490-5497. [CrossRef]

11. Forutan, M.; Ansari Mahyari, S.; Baes, C.; Melzer, N.; Schenkel, F.S.; Sargolzaei, M. Inbreeding and runs of homozygosity before and after genomic selection in North American Holstein cattle. BMC Genom. 2018, 19, 98. [CrossRef] 
12. Cassell, B.G.; Adamec, V.; Pearson, R.E. Effect of Incomplete Pedigrees on Estimates of Inbreeding and Inbreeding Depression for Days to First Service and Summit Milk Yield in Holsteins and Jerseys. J. Dairy Sci. 2003, 86, 2967-2976. [CrossRef]

13. Curik, I.; Ferenčaković, M.; Sölkner, J. Inbreeding and runs of homozygosity: A possible solution to an old problem. Livest. Sci. 2014, 166, 26-34. [CrossRef]

14. VanRaden, P.M. Efficient Methods to Compute Genomic Predictions. J. Dairy Sci. 2008, 91, 4414-4423. [CrossRef] [PubMed]

15. Marras, G.; Gaspa, G.; Sorbolini, S.; Dimauro, C.; Ajmone-Marsan, P.; Valentini, A.; Williams, J.L.; Macciotta, N.P.P. Analysis of runs of homozygosity and their relationship with inbreeding in five cattle breeds farmed in Italy. Anim. Genet. 2015, 46, 110-121. [CrossRef] [PubMed]

16. McQuillan, R.; Leutenegger, A.-L.; Abdel-Rahman, R.; Franklin, C.S.; Pericic, M.; Barac-Lauc, L.; Smolej-Narancic, N.; Janicijevic, B.; Polasek, O.; Tenesa, A.; et al. Runs of Homozygosity in European Populations. Am. J. Hum. Genet. 2008, 83, 359-372. [CrossRef]

17. Brüniche-Olsen, A.; Kellner, K.F.; Anderson, C.J.; DeWoody, J.A. Runs of homozygosity have utility in mammalian conservation and evolutionary studies. Conserv. Genet. 2018, 19, 1295-1307. [CrossRef]

18. Falconer, D.S.; Mackay, T.F.C. Introduction to Quantitative Genetics; Pearson, P.H., Ed.; Longman: Harlow, UK, 1996.

19. Peripolli, E.; Munari, D.P.; Silva, M.V.G.B.; Lima, A.L.F.; Irgang, R.; Baldi, F. Runs of homozygosity: Current knowledge and applications in livestock. Anim. Genet. 2017, 48, 255-271. [CrossRef]

20. MacLeod, I.M.; Larkin, D.M.; Lewin, H.A.; Hayes, B.J.; Goddard, M.E. Inferring demography from runs of homozygosity in whole-genome sequence, with correction for sequence errors. Mol. Biol. Evol. 2013, 30, 2209-2223. [CrossRef]

21. Sams, A.J.; Boyko, A.R. Fine-Scale Resolution of Runs of Homozygosity Reveal Patterns of Inbreeding and Substantial Overlap with Recessive Disease Genotypes in Domestic Dogs. G3 2019, 9, 117-123. [CrossRef]

22. Kirin, M.; McQuillan, R.; Franklin, C.S.; Campbell, H.; McKeigue, P.M.; Wilson, J.F. Genomic Runs of Homozygosity Record Population History and Consanguinity. PLoS ONE 2010, 5, e13996. [CrossRef]

23. Nothnagel, M.; Lu, T.T.; Kayser, M.; Krawczak, M. Genomic and geographic distribution of SNP-defined runs of homozygosity in Europeans. Hum. Mol. Genet. 2010, 19, 2927-2935. [CrossRef]

24. Gurgul, A.; Szmatoła, T.; Topolski, P.; Jasielczuk, I.; Żukowski, K.; Bugno-Poniewierska, M. The use of runs of homozygosity for estimation of recent inbreeding in Holstein cattle. J. Appl. Genet. 2016, 57, 527-530. [CrossRef] [PubMed]

25. Mészáros, G.; Boison, S.A.; Pérez O’Brien, A.M.; Ferenčaković, M.; Curik, I.; Da Silva, M.V.B.; Utsunomiya, Y.T.; Garcia, J.F.; Sölkner, J. Genomic analysis for managing small and endangered populations: A case study in Tyrol Grey cattle. Front. Genet. 2015, 6, 173. [PubMed]

26. Signer-Hasler, H.; Burren, A.; Neuditschko, M.; Frischknecht, M.; Garrick, D.; Stricker, C.; Gredler, B.; Bapst, B.; Flury, C. Population structure and genomic inbreeding in nine Swiss dairy cattle populations. Genet. Sel. Evol. 2017, 49, 83. [CrossRef] [PubMed]

27. Ferenčaković, M.; Hamzić, E.; Gredler, B.; Solberg, T.R.; Klemetsdal, G.; Curik, I.; Sölkner, J. Estimates of autozygosity derived from runs of homozygosity: Empirical evidence from selected cattle populations. J. Anim. Breed. Genet. 2013, 130, 286-293. [CrossRef] [PubMed]

28. Kim, E.-S.; Cole, J.B.; Huson, H.; Wiggans, G.R.; Van Tassell, C.P.; Crooker, B.A.; Liu, G.; Da, Y.; Sonstegard, T.S. Effect of Artificial Selection on Runs of Homozygosity in U.S. Holstein Cattle. PLoS ONE 2013, 8, e80813. [CrossRef]

29. Gomez-Raya, L.; Rodríguez, C.; Barragán, C.; Silió, L. Genomic inbreeding coefficients based on the distribution of the length of runs of homozygosity in a closed line of Iberian pigs. Genet. Sel. Evol. 2015, 47, 81. [CrossRef]

30. Xu, Z.; Sun, H.; Zhang, Z.; Zhao, Q.; Olasege, B.S.; Li, Q.; Yue, Y.; Ma, P.; Zhang, X.; Wang, Q.; et al. Assessment of Autozygosity Derived From Runs of Homozygosity in Jinhua Pigs Disclosed by Sequencing Data. Front. Genet. 2019, 10, 274. [CrossRef]

31. Ai, H.; Huang, L.; Ren, J. Genetic Diversity, Linkage Disequilibrium and Selection Signatures in Chinese and Western Pigs Revealed by Genome-Wide SNP Markers. PLoS ONE 2013, 8, e56001. [CrossRef] 
32. Beynon, S.E.; Slavov, G.T.; Farré, M.; Sunduimijid, B.; Waddams, K.; Davies, B.; Haresign, W.; Kijas, J.; MacLeod, I.M.; Newbold, C.J.; et al. Population structure and history of the Welsh sheep breeds determined by whole genome genotyping. BMC Genet. 2015, 16, 65. [CrossRef]

33. Manunza, A.; Noce, A.; Serradilla, J.M.; Goyache, F.; Martínez, A.; Capote, J.; Delgado, J.V.; Jordana, J.; Muñoz, E.; Molina, A.; et al. A genome-wide perspective about the diversity and demographic history of seven Spanish goat breeds. Genet. Sel. Evol. 2016, 48, 52. [CrossRef]

34. Ghoreishifar, S.M.; Moradi-Shahrbabak, H.; Fallahi, M.H.; Moradi-Shahrbabak, M.; Abdollahi-Arpanahi, R.; Khansefid, M. Genomic measures of inbreeding coefficients and genome-wide scan for runs of homozygosity islands in Iranian river buffalo, Bubalus bubalis. BMC Genet. 2020, 21, 16.

35. Purfield, D.C.; Berry, D.P.; McParland, S.; Bradley, D.G. Runs of homozygosity and population history in cattle. BMC Genet. 2012, 13, 70. [CrossRef] [PubMed]

36. D'Ambrosio, J.; Phocas, F.; Haffray, P.; Bestin, A.; Brard-Fudulea, S.; Poncet, C.; Quillet, E.; Dechamp, N.; Fraslin, C.; Charles, M.; et al. Genome-wide estimates of genetic diversity, inbreeding and effective size of experimental and commercial rainbow trout lines undergoing selective breeding. Genet. Sel. Evol. 2019, 51, 26. [CrossRef] [PubMed]

37. Yañez, J.M.; Bangera, R.; Lhorente, J.P.; Oyarzún, M.; Neira, R. Quantitative genetic variation of resistance against Piscirickettsia salmonis in Atlantic salmon (Salmo salar). Aquaculture 2013, 414, 155-159. [CrossRef]

38. Yáñez, J.M.; Lhorente, J.P.; Bassini, L.N.; Oyarzún, M.; Neira, R.; Newman, S. Genetic co-variation between resistance against both Caligus rogercresseyi and Piscirickettsia salmonis, and body weight in Atlantic salmon (Salmo salar). Aquaculture 2014, 433, 295-298. [CrossRef]

39. Barria, A.; Christensen, K.A.; Yoshida, G.; Jedlicki, A.; Leong, J.S.; Rondeau, E.B.; Lhorente, J.P.; Koop, B.F.; Davidson, W.S.; Yáñez, J.M. Whole genome linkage disequilibrium and effective population size in a coho salmon (Oncorhynchus kisutch) breeding population using a high density SNP array. Front. Genet. 2019, 10, 498. [CrossRef]

40. Purcell, S.; Neale, B.; Todd-Brown, K.; Thomas, L.; Ferreira, M.A.R.; Bender, D.; Maller, J.; Sklar, P.; de Bakker, P.I.W.; Daly, M.J.; et al. PLINK: A tool set for whole-genome association and population-based linkage analyses. Am. J. Hum. Genet. 2007, 81, 559-575. [CrossRef]

41. R Core Team. R: A Language and Environment for Statistical Computing; R Foundation for Statistical Computing: Vienna, Austria, 2015.

42. Pritchard, J.K.; Stephens, M.; Rosenberg, N.A.; Donnelly, P. Association Mapping in Structured Populations. Am. J. Hum. Genet. 2000, 67, 170-181. [CrossRef]

43. Evanno, G.; Regnaut, S.; Goudet, J. Detecting the number of clusters of individuals using the software structure: A simulation study. Mol. Ecol. 2005, 14, 2611-2620. [CrossRef]

44. Biscarini, F.; Cozzi, P.; Gaspa, G.; Marras, G. Detect Runs of Homozygosity and Runs of Heterozygosity in Diploid Genomes. CRAN. Available online: https://cran.r-project.org/web/checks/check_results_detectRUNS. html (accessed on 24 October 2019).

45. Wright, S. Genetics of populations. Encycl. Br. 1948, 10, 111-112.

46. Legarra, A.; Aguilar, I.; Misztal, I. A relationship matrix including full pedigree and genomic information. J. Dairy Sci. 2009, 92, 4656-4663. [CrossRef] [PubMed]

47. Allendorf, F.W.; Phelps, S.R. Loss of Genetic Variation in a Hatchery Stock of Cutthroat Trout. Trans. Am. Fish. Soc. 1980, 109, 537-543. [CrossRef]

48. Gibson, J.; Morton, N.E.; Collins, A. Extended tracts of homozygosity in outbred human populations. Hum. Mol. Genet. 2006, 15, 789-795. [CrossRef] [PubMed]

49. Ceballos, F.C.; Joshi, P.K.; Clark, D.W.; Ramsay, M.; Wilson, J.F. Runs of homozygosity: Windows into population history and trait architecture. Nat. Rev. Genet. 2018, 19, 220-234. [CrossRef] [PubMed]

50. Broman, K.W.; Weber, J.L. Long Homozygous Chromosomal Segments in Reference Families from the Centre d'Étude du Polymorphisme Humain. Am. J. Hum. Genet. 1999, 65, 1493-1500. [CrossRef]

51. Zhang, Q.; Calus, M.P.; Guldbrandtsen, B.; Lund, M.S.; Sahana, G. Estimation of inbreeding using pedigree, 50k SNP chip genotypes and full sequence data in three cattle breeds. BMC Genet. 2015, 16, 88. [CrossRef] [PubMed]

52. Peripolli, E.; Stafuzza, N.B.; Munari, D.P.; Lima, A.L.F.; Irgang, R.; Machado, M.A.; Panetto, J.C.d.C.; Ventura, R.V.; Baldi, F.; da Silva, M.V.G.B. Assessment of runs of homozygosity islands and estimates of genomic inbreeding in Gyr (Bos indicus) dairy cattle. BMC Genomics 2018, 19, 34. [CrossRef] 
53. Zhang, Z.; Zhang, Q.; Xiao, Q.; Sun, H.; Gao, H.; Yang, Y.; Chen, J.; Li, Z.; Xue, M.; Ma, P.; et al. Distribution of runs of homozygosity in Chinese and Western pig breeds evaluated by reduced-representation sequencing data. Anim. Genet. 2018, 49,579-591. [CrossRef]

54. Howard, J.T.; Tiezzi, F.; Huang, Y.; Gray, K.A.; Maltecca, C. Characterization and management of long runs of homozygosity in parental nucleus lines and their associated crossbred progeny. Genet. Sel. Evol. 2016, 48, 91. [CrossRef]

55. Cardoso, T.F.; Amills, M.; Bertolini, F.; Rothschild, M.; Marras, G.; Boink, G.; Jordana, J.; Capote, J.; Carolan, S.; Hallsson, J.H.; et al. Patterns of homozygosity in insular and continental goat breeds. Genet. Sel. Evol. 2018, 50, 56. [CrossRef]

56. Bertolini, F.; Cardoso, T.F.; Marras, G.; Nicolazzi, E.L.; Rothschild, M.F.; Amills, M. Genome-wide patterns of homozygosity provide clues about the population history and adaptation of goats. Genet. Sel. Evol. 2018, 50, 59. [CrossRef] [PubMed]

57. Onzima, R.B.; Upadhyay, M.R.; Doekes, H.P.; Brito, L.F.; Bosse, M.; Kanis, E.; Groenen, M.A.M.; Crooijmans, R.P.M.A. Genome-Wide Characterization of Selection Signatures and Runs of Homozygosity in Ugandan Goat Breeds. Front. Genet. 2018, 9, 318. [CrossRef] [PubMed]

58. Morales-González, E.; Saura, M.; Fernández, A.; Fernández, J.; Pong-Wong, R.; Cabaleiro, S.; Martínez, P.; Martín-García, A.; Villanueva, B. Evaluating different genomic coancestry matrices for managing genetic variability in turbot. Aquaculture 2020, 520, 734985. [CrossRef]

59. Wang, J. Marker-based estimates of relatedness and inbreeding coefficients: An assessment of current methods. J. Evol. Biol. 2014, 27, 518-530. [CrossRef] [PubMed]

60. Kardos, M.; Luikart, G.; Allendorf, F.W. Measuring individual inbreeding in the age of genomics: Marker-based measures are better than pedigrees. Heredity 2015, 115, 63-72. [CrossRef] [PubMed]

61. Keller, M.C.; Visscher, P.M.; Goddard, M.E. Quantification of inbreeding due to distant ancestors and its detection using dense single nucleotide polymorphism data. Genetics 2011, 189, 237-249. [CrossRef]

62. Mastrangelo, S.; Tolone, M.; Di Gerlando, R.; Fontanesi, L.; Sardina, M.T.; Portolano, B. Genomic inbreeding estimation in small populations: Evaluation of runs of homozygosity in three local dairy cattle breeds. Animal 2016, 10, 746-754. [CrossRef]

63. Purfield, D.C.; McParland, S.; Wall, E.; Berry, D.P. The distribution of runs of homozygosity and selection signatures in six commercial meat sheep breeds. PLoS ONE 2017, 12, e0176780. [CrossRef]

64. Sumreddee, P.; Toghiani, S.; Hay, E.H.; Roberts, A.; Agrrey, S.E.; Rekaya, R. Inbreeding depression in line Hereford cattle population using pedigree and genomic information. J. Anim. Sci. 2019, 97, 1-18. [CrossRef]

65. Zavarez, L.B.; Utsunomiya, Y.T.; Carmo, A.S.; Neves, H.H.R.; Brien, A.M.P.O.; Curik, I.; Cole, J.B.; Carvalheiro, R.; Feren, M.; Tassell, V.; et al. Assessment of autozygosity in Nellore cows (Bos indicus) through high-density SNP genotypes. Front. Genet. 2015, 6, 1-8. [CrossRef]

66. Lencz, T.; Lambert, C.; DeRosse, P.; Burdick, K.E.; Morgan, T.V.; Kane, J.M.; Kucherlapati, R.; Malhotra, A.K. Runs of homozygosity reveal highly penetrant recessive loci in schizophrenia. Proc. Natl. Acad. Sci. USA 2007, 104, 19942-19947. [CrossRef] [PubMed]

67. Bosse, M.; Megens, H.-J.; Madsen, O.; Paudel, Y.; Frantz, L.A.F.; Schook, L.B.; Crooijmans, R.P.M.A.; Groenen, M.A.M. Regions of Homozygosity in the Porcine Genome: Consequence of Demography and the Recombination Landscape. PLoS Genet. 2012, 8, e1003100. [CrossRef] [PubMed]

68. Traspov, A.; Deng, W.; Kostyunina, O.; Ji, J.; Shatokhin, K.; Lugovoy, S.; Zinovieva, N.; Yang, B.; Huang, L. Population structure and genome characterization of local pig breeds in Russia, Belorussia, Kazakhstan and Ukraine. Genet. Sel. Evol. 2016, 48, 16. [CrossRef] [PubMed]

69. Goszczynski, D.; Molina, A.; Terán, E.; Morales-Durand, H.; Ross, P.; Cheng, H.; Giovambattista, G.; Demyda-Peyrás, S. Runs of homozygosity in a selected cattle population with extremely inbred bulls: Descriptive and functional analyses revealed highly variable patterns. PLoS ONE 2018, 13, e0200069. [CrossRef] [PubMed]

70. Smitherman, R.O.; Tave, D. Maintenance of genetic quality in cultured tilapia. Asian Fish. Sci. 1987, 1, 75-82.

(C) 2020 by the authors. Licensee MDPI, Basel, Switzerland. This article is an open access article distributed under the terms and conditions of the Creative Commons Attribution (CC BY) license (http://creativecommons.org/licenses/by/4.0/). 